University of Wollongong

Research Online

Australian Institute for Innovative Materials -

Papers

Australian Institute for Innovative Materials

$1-1-2015$

\title{
Edge-hydroxylated boron nitride nanosheets as an effective additive to improve the thermal response of hydrogels
}

\author{
Feng Xiao \\ University of Wollongong, fx873@uowmail.edu.au \\ Sina Naficy \\ University of Wollongong, snaficy@uow.edu.au \\ Gilberto Casillas \\ University of Wollongong, gilberto@uow.edu.au \\ Majharu Haque Khan \\ University of Wollongong, mhk467@uowmail.edu.au \\ Tomas Katkus \\ University of Wollongong, tk344@uowmail.edu.au
}

See next page for additional authors

Follow this and additional works at: https://ro.uow.edu.au/aiimpapers

Part of the Engineering Commons, and the Physical Sciences and Mathematics Commons

Research Online is the open access institutional repository for the University of Wollongong. For further information contact the UOW Library: research-pubs@uow.edu.au 


\title{
Edge-hydroxylated boron nitride nanosheets as an effective additive to improve the thermal response of hydrogels
}

\author{
Abstract \\ Upon flowing hot steam over hexagonal boron nitride (h-BN) bulk powder, efficient exfoliation and \\ hydroxylation of BN occur simultaneously. Through effective hydrogen bonding with water and $\mathrm{N}$ - \\ isopropylacrylamide, edge-hydroxylated $\mathrm{BN}$ nanosheets dramatically improve the dimensional change and \\ dye release of this temperature-sensitive hydrogel and thereby enhance its efficacy in bionic, soft robotic, \\ and drug-delivery applications.
}

\section{Keywords}

improve, additive, effective, nanosheets, hydroxylated, nitride, hydrogels, boron, edge, thermal, response

Disciplines

Engineering | Physical Sciences and Mathematics

\section{Publication Details}

Xiao, F., Naficy, S., Casillas, G., Khan, M. H., Katkus, T., Jiang, L., Liu, H., Li, H. \& Huang, Z. (2015). Edgehydroxylated boron nitride nanosheets as an effective additive to improve the thermal response of hydrogels. Advanced Materials, 27 (44), 7196-7203.

\section{Authors}

Feng Xiao, Sina Naficy, Gilberto Casillas, Majharu Haque Khan, Tomas Katkus, Lei Jiang, Hua-Kun Liu, Huijun Li, and Zhenguo Huang 


\section{WILEY-VCH}

DOI: $10.1002 /(($ please add manuscript number $))$

Article type: Communication

\section{Edge-hydroxylated Boron Nitride Nanosheets as an Effective Additive to Improve the Thermal Response of Hydrogels}

Feng Xiao, Sina Naficy, Gilberto Casillas, Majharul H. Khan, Tomas Katkus, Lei Jiang, Huakun Liu, Huijun Li, Zhenguo Huang*

F. Xiao, M. H. Khan, T. Katkus, Prof. H. K. Liu, Dr. Z. Huang

Institute for Superconducting and Electronic Materials

University of Wollongong

Wollongong, NSW 2500, Australia

E-mail: zhenguo@uow.edu.au

Dr. S. Naficy

Intelligent Polymer Research Institute and ARC Centre of Excellence for Electromaterials

Science

University of Wollongong

Wollongong, NSW 2500, Australia

Dr. G. Casillas

Electron Microscopy Center

University of Wollongong

Wollongong, NSW 2500, Australia

Prof. L. Jiang

Beijing National Laboratory of Molecular Sciences (BNLMS), Key Laboratory of Organic Solids, Institute of Chemistry

Chinese Academy of Sciences

Beijing 100190, P.R. China

Prof. H. J. Li

School of Mechanical, Materials and Mechatronic Engineering

University of Wollongong

Wollongong, NSW 2500, Australia

Keywords: boron nitride, nanosheets, hydroxyl, functionalization, temperature sensitive hydrogel

Isostructural to graphene, single-layer hexagonal boron nitride ( $h$-BN) has alternating boron and nitrogen atoms replacing carbon atoms in a $s p^{2}$-bonded two-dimensional layer. ${ }^{[1]}$ Due to its atomically flat and electrically insulating surface, the $h$-BN nanosheet (BNNS) has been considered as an ideal substrate for graphene-based electronics. ${ }^{[2]}$ In contrast to the covalent C-C bond of graphene, the ionic nature of the B-N bond makes BNNS highly resistant to oxidation (stable up to $840{ }^{\circ} \mathrm{C}$ in air) ${ }^{[3]}$ and to corrosion. ${ }^{[4]}$ Additionally, BNNS shows 


\section{WILEY-VCH}

excellent mechanical properties and thus has been extensively applied as a lubricant in harsh environments. ${ }^{[5]}$ More interestingly, BNNS has excellent thermal conductivity, which makes it an efficient filler to improve the thermal performance of liquids ${ }^{[6,7]}$ and solid polymeric composites. ${ }^{[8]}$ For all these applications, a facile method to synthesize high-quality BNNS is a prerequisite to take full advantage of its intrinsic properties.

The methods for the preparation of BNNS have been quite limited and inefficient, compared with the facile methods for the large scale production of graphene. So far, the most common way of producing BNNS is via sonication-assisted exfoliation of bulk $h$-BN powder. To overcome the van der Waals forces between the layers, the liquid media/solvents for effective exfoliation should have similar surface energy to that of $h$-BN. ${ }^{[9]}$ Mono- and few-layered BNNS have been prepared by sonicating $h$-BN in media such as water, isopropanol, and $N$ methyl-2-pyrrolidone. ${ }^{[10-12]}$ A complete removal of some of the solvents, however, can be hampered by their high boiling points. Compared with the numerous reports on functionalized graphene, only a few papers have been published on functionalizing $h$ - $\mathrm{BN}$, which is likely due to its exceptional chemical stability. Simulations have indicated that effective functionalization of BNNS can change its band gap and consequently lead to applications in various fields. ${ }^{[13]}$ Experimentally, hydroxyl functionalized BNNS (OH-BNNS) has been synthesized via various methods, including sonicating bulk $h$-BN powder in water, ${ }^{[10]}$ heating bulk $h$-BN powder in air, ${ }^{[14]}$ treating $h$-BN powder in hot $\mathrm{H}_{2} \mathrm{SO}_{4} / \mathrm{KMnO}_{4}$ aqueous solution, ${ }^{[15]}$ chemical reactions between $g-\mathrm{C}_{3} \mathrm{~N}_{4}$ and $\mathrm{B}(\mathrm{OH})_{3},{ }^{[16]}$ and oxygen radical functionalization followed by hydrolytic defunctionalization. ${ }^{[12]}$ The presence of $\mathrm{OH}$ groups could alter the surface energy and thus ameliorate the solubility of BNNS in a variety of solvents. Being very common in nature, hydroxyl $(\mathrm{OH})$ groups can interact with various forms of inorganic and organic matter, and therefore, the intrinsic properties of BNNS can be better exploited by 


\section{WILEY-VCH}

grafting $\mathrm{OH}$ groups. For example, $\mathrm{OH}-\mathrm{BNNS}$ has been very effective for polymer reinforcement ${ }^{[12]}$ and drug delivery. ${ }^{[16]}$

Herein, we demonstrate a one-step route whereby commercial $h$-BN can be directly exfoliated by a steam treatment and simultaneously functionalized to yield OH-BNNS (Figure 1a). This procedure is simple, low-cost, free of harsh chemicals, and can be readily scaled up.

Furthermore, we demonstrate that the functionalization occurs predominantly along the platelet edge. The resultant excellent dispersion and stability of OH-BNNS in aqueous solution and organic solutions make it an effective additive to $N$-isopropylacrylamide based hydrogels, leading to much enhanced thermal conductivity without compromising the mechanical properties. The resulting hydrogels demonstrate faster dimensional change and dye desorption upon heating.

Stable dispersions of $\sim 0.3 \mathrm{mg} / \mathrm{mL}$ OH-BNNS in water and $\sim 0.06 \mathrm{mg} / \mathrm{mL} \mathrm{OH-BNNS}$ in ethanol (photographic images in Figure S1a and b, preparation process in the Supporting Information) appear translucent, and the concentrations are much higher than those for BNNS with negligible amounts of hydroxyl groups ${ }^{[17]}$ and are consistent with previous reports. ${ }^{[7,10}$, ${ }^{14]}$ The scanning electron microscope (SEM) studies show that the as-received $h$-BN (Supporting Information Figure S2) powders consist of thick platelets with smooth surfaces and edges, and the lateral size is from 1 to 7 microns. The OH-BNNS (Supporting Information Figure S2a-c) obtained at $850^{\circ} \mathrm{C}$ appears to be transparent due to the much reduced thickness, but with a slightly reduced lateral size ranging from submicron to several microns. This is much larger than the exfoliated OH-BNNS in previous reports. ${ }^{[10,14,17]}$ When the temperature was increased to $1000^{\circ} \mathrm{C}$, smaller sheets with more noticeable voids in the plane were obtained (Supporting Information Figure S2d-e). This morphology is very similar to that in previous reports, ${ }^{[14,17]}$ where prolonged sonication was applied to exfoliate the $h$-BN. 


\section{WILEY-VCH}

The formation of small sheets with many defects will have a negative impact on the heat transfer along the plane. Therefore, a low temperature, $850{ }^{\circ} \mathrm{C}$ in this case, has been selected to produce large OH-BNNS with fewer defects.

Figure $1 \mathrm{~b}$ shows TEM images of OH-BNNS with morphology similar to the parent $h$-BN powder. The Moiré pattern is associated with the restacked few-layered OH-BNNS with different orientations, which has been observed in the case of graphene. ${ }^{[18]}$ Few-layered OHBNNS can be clearly seen in high magnification transmission electron microscope (TEM) images (Figure 1c and Supporting Information Figure S2f). The electron diffraction pattern (inset of Figure 1c) reveals the typical six-fold symmetry of $h$-BN, indicative of the structural integrity after the exfoliation. Atomic force microscope (AFM) topographic images of $\mathrm{OH}-$ BNNS were acquired via tapping mode. Isolated OH-BNNS with a thickness of $\sim 1 \mathrm{~nm}$ and lateral size of approximately $2 \mu \mathrm{m}$ was observed (Figure 1d). A terraced morphology showing a mono-layered OH-BNNS joined to a tri-layered OH-BNNS can be seen, taking into account the solvents trapped between the OH-BNNS and the silicon substrate. ${ }^{[19]}$ The result is in good agreement with that in Figure 1c, further supporting the effective exfoliation of $h$-BN during the treatment.

Similar to other nitrides, including $\mathrm{Si}_{3} \mathrm{~N}_{4}, \mathrm{TiN}$, and $\mathrm{CrN}, h$-BN is also sensitive to moisture at elevated temperatures, due to the strong affinity of $\mathrm{N}$ towards $\mathrm{O}$ in $\mathrm{H}_{2} \mathrm{O} \cdot{ }^{[20]}$ After the heat treatment under hot steam, white ammonium pentaborate tetrahydrate $\left(\mathrm{NH}_{4} \mathrm{~B}_{5} \mathrm{O}_{8} \cdot 4 \mathrm{H}_{2} \mathrm{O}\right)$ powder is deposited on the inner wall of the quartz tube downstream of the Ar outlet, ${ }^{[21]}$ as confirmed by the X-ray diffraction (XRD) analysis (Supporting Information Figure S3). The initially pure deionized water in the disposal unit has a high level of ammonia, as confirmed by the Nessler's reagent test (Supporting Information Figure S4). The overall reaction can be 


\section{WILEY-VCH}

described in Equation (1), which has also been observed before. ${ }^{[10,22]}$ The formation of $\mathrm{NH}_{4} \mathrm{~B}_{5} \mathrm{O}_{8} \cdot 4 \mathrm{H}_{2} \mathrm{O}$ is due to the reaction between $\mathrm{NH}_{3}$ and $\mathrm{H}_{3} \mathrm{BO}_{3}$.

The exfoliation is facilitated by the hydrolysis reaction at these high temperatures with the release of ammonia gas. The high thermal input at these temperatures would weaken the van der Waals forces between the $\mathrm{BN}$ layers. The hot $\mathrm{H}_{2} \mathrm{O}$ gradually reacts with $h$-BN, forming voids (size depending on the temperature and reaction duration) on the (002) basal plane and along the edges, which would further weaken the van der Waals forces. The highly dynamic $\mathrm{H}_{2} \mathrm{O}$ and $\mathrm{NH}_{3}$ formed in-situ at such high temperatures may therefore penetrate through these voids and diffuse slowly between the BN layers, causing exfoliation, as evidenced by the SEM and TEM images (Figure 1b, c). AFM was used to measure the statistical thickness of the $\mathrm{OH}-\mathrm{BNNS}^{[11]}$ (Figure S1c), which confirms that the final product has a thickness that mainly varies from 1 to $5 \mathrm{~nm}$, with $20 \%$ being $1-2 \mathrm{~nm}$ and over $60 \%$ being $3-4 \mathrm{~nm}$. This method gives a high yield of $>30 \%$ for few-layered BNNS in the products. The yield of OHBNNS could be controlled by optimizing the synthesis temperature and reaction duration. We found that the reaction rate is slow at $850{ }^{\circ} \mathrm{C}$ and the weight loss is only $5 \%$ in $2 \mathrm{~h}$, suggesting that at this stage the majority of BN nanosheets remain as the solid product. Higher temperatures contribute to the formation of boric acid and consequently reduce the yields (Tables S1 and S2).

The functionalization occurs simultaneously with the hydrolysis, as illustrated in Figure 1a. The driving force of the reaction is believed to be the formation of $\mathrm{NH}_{3}$ as a leaving group. The exposed B atoms with dangling bonds then react with hydroxyl groups. The reaction in Equation (1) describes a situation where charge neutral $\mathrm{H}_{3} \mathrm{BO}_{3}$ is formed. In reality, tetrahedrally coordinated $\mathrm{N}_{3} \mathrm{~B}(\mathrm{OH})$ is also formed. ${ }^{[16]}$ The presence of $-\mathrm{B}(\mathrm{OH})$ can be verified using Fourier transform infrared (FTIR) spectroscopy and XRD. ${ }^{[10,12,23]}$ 


\section{WILEY-VCH}

Two strong FTIR bands at $\sim 1343 \mathrm{~cm}^{-1}$ and $\sim 807 \mathrm{~cm}^{-1}$ are present in pristine $h$-BN, $h$-BN treated at $850{ }^{\circ} \mathrm{C}(\mathrm{BN}-850)$, and $h$-BN treated at $900{ }^{\circ} \mathrm{C}(\mathrm{BN}-900)$ (Figure 2a), which are correlated with the in-plane stretching and the out-of-plane bending mode of $h$-BN, respectively. ${ }^{[24]}$ The red-shifts from $807 \mathrm{~cm}^{-1}$ for pristine $h$-BN to $787 \mathrm{~cm}^{-1}$ for BN-850, and $784 \mathrm{~cm}^{-1}$ for BN-900, are due to the disruption by hydroxyl groups, which leads to vibration at lower wavenumber. ${ }^{[12]} \mathrm{A}$ peak at $3440 \mathrm{~cm}^{-1}$, assigned to the $\mathrm{O}-\mathrm{H}$ stretching mode from the $\mathrm{N}_{3} \mathrm{~B}(\mathrm{OH})$ unit, appears in the $\mathrm{BN}-850$, which is consistent with previous results. ${ }^{[10,12,15,16]}$ Reactions at lower temperatures would not lead to an observable band at $3440 \mathrm{~cm}^{-1}$ (not shown here). For the $\mathrm{BN}-900$, the $\mathrm{O}-\mathrm{H}$ stretching mode at $3206 \mathrm{~cm}^{-1}$ and a new bending mode at $1200 \mathrm{~cm}^{-1}$ appear simultaneously, which are correlated with $\mathrm{H}_{3} \mathrm{BO}_{3}$, where boron is triangularly coordinated with oxygen. ${ }^{[25]}$ This is confirmed by the XRD pattern (Figure 2b) of BN-900, where diffraction peaks associated with $\mathrm{H}_{3} \mathrm{BO}_{3}$ are clearly visible. ${ }^{[14]}$ Based on the results obtained, we propose the following explanation. $\mathrm{H}_{3} \mathrm{BO}_{3}$ has a low decomposition point $\left(\sim 170^{\circ} \mathrm{C}\right)$, but under the hot steam in the quartz tube, it can survive high temperatures. Additionally, it also has a low boiling point of $300^{\circ} \mathrm{C}$, so it could evaporate away quickly. Based on the $\mathrm{NH}_{4} \mathrm{~B}_{5} \mathrm{O}_{8} \cdot 4 \mathrm{H}_{2} \mathrm{O}$ white powder obtained at the downstream outlet of the tube (for all the temperatures), it can be reasoned that most of the $\mathrm{H}_{3} \mathrm{BO}_{3}$ has been evaporated away. At $850{ }^{\circ} \mathrm{C}$, the evaporation rate is relatively faster than the formation rate of $\mathrm{H}_{3} \mathrm{BO}_{3}$, leaving no $\mathrm{H}_{3} \mathrm{BO}_{3}$ in the final product. At $900{ }^{\circ} \mathrm{C}$ a reverse trend occurs, and $\mathrm{H}_{3} \mathrm{BO}_{3}$ was observed in the final product, as confirmed by FTIR and XRD. The reactions were tried at higher temperatures with more $\mathrm{H}_{3} \mathrm{BO}_{3}$ observed in the final product (Table S1). Therefore, by adopting the optimum temperature, $850^{\circ} \mathrm{C}$ in this case, $\mathrm{OH}-\mathrm{BNNS}$ can be obtained with an undetectable amount of impurities after a single heat treatment. Furthermore, the resultant OH-BNNS can be directly dispersed in solvents to be used as additives, avoiding tedious purification processes such as washing, centrifuging, and drying, which have been typically applied in the preparation of OH-BNNS. ${ }^{[12,17,26]}$ The Raman spectra (Figure 2c) contain 


\section{WILEY-VCH}

bands at $1362 \mathrm{~cm}^{-1}(\mathrm{BN}-850)$ and $1360 \mathrm{~cm}^{-1}$ (BN-900), close to $1366 \mathrm{~cm}^{-1}$ for the commercial $h$-BN, all of which can be attributed to the $\mathrm{E}_{2 \mathrm{~g}}$ mode vibration of $h$-BN. The slight red-shifts of $4 \mathrm{~cm}^{-1}(\mathrm{BN}-850)$ and $6 \mathrm{~cm}^{-1}(\mathrm{BN}-900)$ in relation to that of the pristine $h$-BN are another piece of evidence that the bulk $h$-BN has been exfoliated to produce predominantly fewlayered nanosheets, which feature reduced interlayer interactions and shortening of the B-N bond. ${ }^{[12]}$

FTIR and X-ray photoelectron spectroscopy (XPS) have been often used to validate the formation of $\mathrm{OH}-\mathrm{BNNS}$, but the location of $\mathrm{OH}$ groups on the plane has been vaguely described. ${ }^{[12,15,23]}$ Aberration-corrected TEM is one of the most powerful tools to characterize matter at the sub-nanometer level. It is typically coupled with energy dispersive X-ray spectroscopy (EDS) to unequivocally identify elements present in the structure. EDS, however, is not reliable for light elements ( $\mathrm{O}$ and lighter) due to many experimental factors. This limitation is overcome by the use of electron energy loss spectroscopy (EELS), where the light elements can be detected with the same resolution as the microscope. Here, we have employed EELS to probe the location of the $\mathrm{OH}$ groups in the BN sheets (Figure 3). Note that in these TEM images, the edges have the same intensity as the interior of the sheet, indicating that it is not a folding but a flat edge. We can see the O-K peak at $\sim 532 \mathrm{eV}$ in areas 2 and 3, which are along the edges of the OH-BNNS, and the disappearance of the O-K peak in areas 4, 5, and 6, which are away from the edges suggesting that the BNNS have been functionalized predominately on the edges rather than on the basal plane (Supporting Information Figure S5). In addition, the presence of $1 \mathrm{~s}-\pi^{*}$ and $1 \mathrm{~s}-\sigma^{*}$ peaks of the N-K edge confirms that the intrinsic hexagonal structure of $h$-BN still remains.

Herein, we demonstrate the use of OH-BNNS as an effective additive to enhance the thermal response of poly( $N$-isopropylacrylamide) (PNIPAM) hydrogel. PNIPAM is one of the most 


\section{WILEY-VCH}

widely studied temperature sensitive hydrogels, with applications ranging from drug delivery to various types of smart systems. ${ }^{[27]}$ The efficacy of these applications is highly dependent on the critical response of the hydrogel to changes in temperature, which in most cases needs to be extremely fast. To take full advantage of the high thermal conductivity of $h$-BN as an additive, it is critical to well disperse the $h$-BN in the hydrogel network, which is not easy due to its hydrophobicity. In this work, the Raman mapping indicates that OH-BNNS is uniformly embedded in the hydrogel matrix rather than forming scattered aggregates (Figure 4c and 4d), The excellent dispersion can be ascribed to the extensive hydrogen bond network between the hydroxyl groups on the BNNS and $N$-isopropylacrylamide (Figure 4a). Such a uniform distribution would effectively favor the exploitation of the high intrinsic thermal conductivity of the BNNS, which consequently enhances heat transfer throughout the hydrogel network.

As a well-known temperature sensitive hydrogel, PNIPAM becomes opaque and shrinks at the same time when heated above $\sim 32^{\circ} \mathrm{C}$, and it returns back to its initial state when the temperature is reduced below the transition temperature. A faster change in opacity and size indicates a better temperature response, which is critical for practical applications. Such an improvement was observed in the response of our PNIPAM/OH-BNNS hydrogels to temperature changes. The addition of only $0.07 \mathrm{wt} \%$ (based on polymer precursor) OH-BNNS to the hydrogel improved the thermal conductivity by $41 \%$ (Figure 5a). When the PNIPAM/OH-BNNS hydrogel composite and pure PNIPAM were taken out of warm water at $50{ }^{\circ} \mathrm{C}$, the former showed a much faster change in transparency than the latter, with a maximum $40 \%$ margin (Figure 5b), indicative of the pivotal role of OH-BNNS in the thermal enhancement.

As the dimensions of the hydrogel have an inverse temperature dependence, another test was carried out to compare the rate of the length change of cylindrical samples when the 


\section{WILEY-VCH}

temperature was increased from room temperature to $50^{\circ} \mathrm{C}$. Both hydrogels were made under the exact same conditions with the same dimensions. The PNIPAM/OH-BNNS hydrogel composite shows faster length change (inset in Figure 5c). Specifically, the greatest difference in length appears at 30 seconds, when the hydrogel composite has shrunk to $3.8 \mathrm{~cm}$ from 4.2 $\mathrm{cm}$, a 5-fold greater shrinking rate than that of its neat counterpart, which has shrunk from 4.2 $\mathrm{cm}$ to $4.15 \mathrm{~cm}$. Finally, after 6 minutes, the lengths of both hydrogels are nearly the same. The faster response rate is attributed to the highly improved thermal conductivity across the composite due to the presence of $\mathrm{OH}-\mathrm{BNNS}$ sheets. This faster change in dimension would make the PNIPAM/OH-BNNS hydrogel composite a better candidate for actuator applications (e.g. valves) that work by thermal stimulation.

Dye release from the hydrogels was also tested, which provides a simple simulation of the releasing process for drug solutions. Since PNIPAM hydrogels undergo large volume deformation upon heating, the drug molecules can be "squeezed" out of the hydrogel composite. Blue dye (blue food coloring) was loaded on both neat and composite hydrogels in the same petri dish, until both reached equilibrium with an identical dark blue color, as perceived by human eyes. They were then put into warm water $\left(T=40^{\circ} \mathrm{C}\right)$ for dye release. After 0.5 minutes, the PNIPAM/OH-BNNS hydrogel began releasing the dye, while the neat hydrogel showed no detectable change in color (Figure 5d). At 3 minutes, the color of the PNIPAM/OH-BNNS hydrogel became a lighter blue, indicating that more dye had been released during the same period than for the neat hydrogel. The faster dye release upon temperature change again indicates that the well-dispersed OH-BNNS improves heat conductivity. PNIPAM/OH-BNNS hydrogels therefore could show a prompt response to their environmental temperature to deliver drug solutions more effectively than the corresponding neat ones. 


\section{WILEY-VCH}

As discussed above, the treatment of bulk $h$-BN powder at high temperatures under steam leads to simultaneous exfoliation and functionalization of the $h$-BN. The resultant OH-BNNS is edge-modified and hydrophilic enough to form good suspensions in water and alcohol. Moreover, when mixed with polymers soluble in water or alcohol, the $\mathrm{OH}$ groups on the nanosheet edges appear to be conducive to a collective interaction between the BNNS and the polymer, most likely through hydrogen bonding, and thus, no phase segregation takes place. This is evidenced by the Raman mapping collected at $1362 \mathrm{~cm}^{-1}$ (Figure $4 \mathrm{c}-\mathrm{d}$ ), which reveals a uniform distribution of BNNS across the hydrogel network. It is important to note that there is no obstacle to using other hydrophilic monomers and polymers to prepare hydrogel composites, so long as the precursors are soluble in water or ethanol. Indeed, we were able to successfully make uniform poly(ethylene glycol)/OH-BNNS and poly(hydroxyethylmethacrylate)/OH-BNNS composites.

It is well known that water-PNIPAM interaction and water-water interaction in the hydrogel is highly sensitive to changes in temperature. Below the lower critical solution temperature (LCST), hydrophilic amide (-NH) and carbonyl (-CO) groups form hydrogen bonds with water molecules, with the interaction dominated by an enthalpic term. Once above the LCST, the entropic gain overcomes the enthalpic term, and water molecules are released. ${ }^{[27]}$ How to effectively transfer the heat to "all" the molecules so to speed up their response is critical for any thermal-stimulus applications. These intermolecular hydrogen bond interactions between water and OH-BNNS, as well as PNIPAM and OH-BNNS, allow the OH-BNNS to act as a thermal carrier to continuously and effectively diffuse the heat throughout the hydrogel composite matrix (Figure 5e), which consequently enhances the thermally stimulated performance of PNIPAM/OH-BNNS hydrogel according to the tests above. The absence of $\mathrm{OH}$ groups on the basal plane is also advantageous, since otherwise, deformation of the BNNS plane would occur, especially in the case of hydrogen bonding. We have also found 


\section{WILEY-VCH}

that $\mathrm{OH}-\mathrm{BNNS}$ can effectively improve the thermal conductivity of the NIPAM/water mixture and even pure water (Supporting Information, Table S3), which is critical, since the hydrogel contains a large amount of water (> $80 \%$ by weight). The improvement is likely due to the high phonon transport along the OH-BNNS basal planes ${ }^{[6,28]}$. The interfacial thermal contact resistance is minimized due to the large contact area between the OH-BNNS and the polymer, as well as the water. In addition, the close interaction through hydrogen bonding will effectively facilitate the transport of phonons between the $\mathrm{BN}$ sheets. We believe that the presence of $\mathrm{OH}$ groups has not appreciably perturbed the crosslinking efficiency of the hydrogel, which significantly affects the response time when the temperature is changed. The swelling (change in mass) ratio of the hydrogel remained unchanged, $\sim 9.2+/-0.1$, when $\mathrm{OH}-$ BNNS was added (at the concentration range studied here). No change was observed in the LCST of the polymer (all around $32{ }^{\circ} \mathrm{C}$ ) upon adding OH-BNNS. In addition, the shrinkage ratios of the hydrogels with and without OH-BNNS are the same, although the rates of dimensional change are different (Figure 5d). Therefore, the thermal enhancement is predominantly caused by the incorporated OH-BNNS.

A simple simulation (Figure S7) indicates that the experimental data are close to the those predicted using a parallel conduction model. ${ }^{[29]}$ It should be noted that, in the parallel model, the conductive filler is arranged in parallel with the direction of thermal flux, which is the most ideal case. It should be noted that the thermal contacts between any interfaces are normally poor. We have confirmed the good dispersion of OH-BNNS in the hydrogel composite with excellent contact between the OH-BNNS and PNIPAM hydrogel through hydrogen bonding. The thermal conductivity of OH-BNNS used for modeling is $360 \mathrm{~W} / \mathrm{mK}$, which is the experimental value for 11-layered $h$-BN with trace of poly(methyl methacrylate)(PMMA), and it was suggested that the ineffective removal of the PMMA residue would degrade the thermal performance. ${ }^{[30]}$ It should also be noted that thermal 


\section{WILEY-VCH}

conductivity of single-layered $h$-BN can be over $1000 \mathrm{~W} / \mathrm{mK} \cdot{ }^{[31]}$ In our case, there is a proportion of few-layered, including monolayer, OH-BNNS, which could contribute more thermal enhancement than relatively thick OH-BNNS. It is thus likely that the experimental value of the $0.04 \mathrm{wt} \%$ loading is close to the simulated value.

The hydrogels need to maintain suitable mechanical properties for practical applications. All polymerization solutions made with OH-BNNS dispersions remained stable for several days until they were polymerized, after which, the nanosheets were fully locked into the network. Over 5 tests, no significant improvement in the Young's modulus was observed when OHBNNS was incorporated into the hydrogel formulation. Some improvements were obtained from compression testing of the hydrogel composites, where PNIPAM/OH-BNNS hydrogels exhibited a higher compression strength and final strain (Supporting Information Figure S8). Notably, BNNS is known to be non-cytotoxic and has been studied for therapeutic or diagnostic applications. ${ }^{[16,32]}$ The PNIPAM/OH-BNNS hydrogel composite is not expected to be cytotoxic either. Therefore, the dramatic improvement in the response to external heat stimulation could be very beneficial for a wide range of bionic and soft robotic applications.

In summary, we have developed a facile and scalable method to directly exfoliate and functionalize intrinsically hydrophobic bulk $h$-BN into hydrophilic OH-BNNS. The hydroxyl groups are predominantly located along the edges of the nanosheets rather than on the basal plane. The excellent dispersibility of OH-BNNS in water and alcohol makes it an effective additive to hydrogels. The intrinsic thermal properties have been perfectly inherited, since the resultant OH-BNNS exhibited large and few-layered morphology rather than the small fragments produced by the sonication-based exfoliation. The PNIPAM/OH-BNNS hydrogel composite shows a much faster thermal response compared to the bare hydrogel, with a $41 \%$ improvement in thermal conductivity achieved by adding only $0.07 \mathrm{wt} \% \mathrm{OH}-\mathrm{BNNS}$. The 


\section{WILEY-VCH}

hydrogel composite also shows faster dimensional change upon heating, with the discrepancy proving that $\mathrm{OH}-\mathrm{BNNS}$ has passed on its excellent thermal properties to the PNIPAM hydrogel. Most interestingly, the dye-release test demonstrates its improved drug delivery capability. According to the merits above, our PNIPAM/OH-BNNS with its superior thermal response is envisaged to be a promising candidate in the field of bionic and soft robotic applications.

((Equation))

$$
\mathrm{BN}+\mathrm{H}_{2} \mathrm{O} \rightarrow \mathrm{NH}_{3}+\mathrm{B}(\mathrm{OH})_{3}
$$

\section{ABBREVIATIONS}

BNNS, boron nitride nanosheet; PNIPAM, poly( $N$-isopropylacrylamide).

\section{Supporting Information}

Supporting Information is available from the Wiley Online Library or from the author.

\section{Acknowledgements}

F. Xiao gratefully acknowledges the Chinese Scholarship Council (CSC) for his scholarship. Z.H. is the recipient of an Australian Research Council Discovery Early Career Research Award (project number DE120101496). S.N. acknowledges the Global Challenges program of the University of Wollongong for funding. This research used equipment located in the UOW Electron Microscopy Centre that was funded by an Australian Research Council (ARC) Linkage, Infrastructure, Equipment and Facilities (LIEF) grant (LE120100104).

Received: ((will be filled in by the editorial staff))

Revised: ((will be filled in by the editorial staff)) Published online: ((will be filled in by the editorial staff)) 


\section{WILEY-VCH}

References

[1] A. Pakdel, Y. Bando, D. Golberg, Chemical Society Reviews 2014, 43, 934; X.-F. Jiang, Q. Weng, X.-B. Wang, X. Li, J. Zhang, D. Golberg, Y. Bando, Journal of Materials Science \& Technology 2015, 31, 589.

[2] M. Wang, S. K. Jang, W.-J. Jang, M. Kim, S.-Y. Park, S.-W. Kim, S.-J. Kahng, J.-Y. Choi, R. S. Ruoff, Y. J. Song, S. Lee, Adv. Mater. 2013, 25, 2746; W. Yang, G. Chen, Z. Shi, C.-C. Liu, L. Zhang, G. Xie, M. Cheng, D. Wang, R. Yang, D. Shi, K. Watanabe, T. Taniguchi, Y. Yao, Y. Zhang, G. Zhang, Nat Mater 2013, 12, 792.

[3] L. H. Li, J. Cervenka, K. Watanabe, T. Taniguchi, Y. Chen, ACS Nano 2014, 8, 1457.

[4] M. Yi, Z. Shen, X. Zhao, S. Liang, L. Liu, Applied Physics Letters 2014, 104.

[5] D.-H. Cho, J.-S. Kim, S.-H. Kwon, C. Lee, Y.-Z. Lee, Wear 2013, 302, 981.

[6] J. Taha-Tijerina, T. N. Narayanan, G. Gao, M. Rohde, D. A. Tsentalovich, M. Pasquali, P. M. Ajayan, ACS Nano 2012, 6, 1214.

[7] W.-L. Song, P. Wang, L. Cao, A. Anderson, M. J. Meziani, A. J. Farr, Y.-P. Sun, Angewandte Chemie 2012, 124, 6604.

[8] C. Zhi, Y. Bando, C. Tang, H. Kuwahara, D. Golberg, Adv. Mater. 2009, 21, 2889;

X.-B. Wang, Q. Weng, X. Wang, X. Li, J. Zhang, F. Liu, X.-F. Jiang, H. Guo, N. Xu, D. Golberg, Y. Bando, ACS Nano 2014, 8, 9081; X. Wang, C. Zhi, L. Li, H. Zeng, C. Li, M. Mitome, D. Golberg, Y. Bando, Adv. Mater. 2011, 23, 4072; H. Zhu, Y. Li, Z. Fang, J. Xu, F. Cao, J. Wan, C. Preston, B. Yang, L. Hu, ACS Nano 2014, 8, 3606; C. Zhi, Y. Xu, Y. Bando, D. Golberg, ACS Nano 2011, 5, 6571; X. Wang, A. Pakdel, J. Zhang, Q. Weng, T. Zhai, C. Zhi, D. Golberg, Y. Bando, Nanoscale Res Lett 2012, 7, 662.

[9] J. N. Coleman, M. Lotya, A. O’Neill, S. D. Bergin, P. J. King, U. Khan, K. Young, A. Gaucher, S. De, R. J. Smith, I. V. Shvets, S. K. Arora, G. Stanton, H.-Y. Kim, K. Lee, G. T. Kim, G. S. Duesberg, T. Hallam, J. J. Boland, J. J. Wang, J. F. Donegan, J. C. Grunlan, G. 


\section{WILEY-VCH}

Moriarty, A. Shmeliov, R. J. Nicholls, J. M. Perkins, E. M. Grieveson, K. Theuwissen, D. W. McComb, P. D. Nellist, V. Nicolosi, Science 2011, 331, 568.

[10] Y. Lin, T. V. Williams, T.-B. Xu, W. Cao, H. E. Elsayed-Ali, J. W. Connell, The Journal of Physical Chemistry C 2011, 115, 2679.

[11] K. R. Paton, E. Varrla, C. Backes, R. J. Smith, U. Khan, A. O’Neill, C. Boland, M. Lotya, O. M. Istrate, P. King, T. Higgins, S. Barwich, P. May, P. Puczkarski, I. Ahmed, M. Moebius, H. Pettersson, E. Long, J. Coelho, S. E. O’Brien, E. K. McGuire, B. M. Sanchez, G. S. Duesberg, N. McEvoy, T. J. Pennycook, C. Downing, A. Crossley, V. Nicolosi, J. N. Coleman, Nat Mater 2014, 13, 624.

[12] T. Sainsbury, A. Satti, P. May, Z. Wang, I. McGovern, Y. K. Gun'ko, J. Coleman, Journal of the American Chemical Society 2012, 134, 18758.

[13] Q. Tang, Z. Zhou, P. Shen, Z. Chen, ChemPhysChem 2013, 14, 1787; Q. Tang, J. Bao, Y. Li, Z. Zhou, Z. Chen, Nanoscale 2014, 6, 8624.

[14] Z. Cui, A. J. Oyer, A. J. Glover, H. C. Schniepp, D. H. Adamson, Small 2014, 10, 2352.

[15] G. R. Bhimanapati, D. Kozuch, J. A. Robinson, Nanoscale 2014, 6, 11671.

[16] Q. Weng, B. Wang, X. Wang, N. Hanagata, X. Li, D. Liu, X. Wang, X. Jiang, Y. Bando, D. Golberg, ACS Nano 2014, 8, 6123.

[17] X. Li, X. Hao, M. Zhao, Y. Wu, J. Yang, Y. Tian, G. Qian, Adv. Mater. 2013, 25, 2200.

[18] Y. Hernandez, V. Nicolosi, M. Lotya, F. M. Blighe, Z. Sun, S. De, I. T. McGovern, B. Holland, M. Byrne, Y. K. Gun'Ko, J. J. Boland, P. Niraj, G. Duesberg, S. Krishnamurthy, R. Goodhue, J. Hutchison, V. Scardaci, A. C. Ferrari, J. N. Coleman, Nat Nano 2008, 3, 563.

[19] Y. Lin, J. W. Connell, Nanoscale 2012, 4, 6908; S. Park, R. S. Ruoff, Nat Nano 2009, 4, 217. 


\section{WILEY-VCH}

[20] S. Motojima, Y. Tamura, K. Sugiyama, Thin Solid Films 1982, 88, 269; C. G. Cofer, J. Economy, Carbon 1995, 33, 389.

[21] T. Matsuda, J Mater Sci 1989, 24, 2353.

[22] T. Saito, F. Honda, Wear 2000, 237, 253.

[23] A. S. Nazarov, V. N. Demin, E. D. Grayfer, A. I. Bulavchenko, A. T. Arymbaeva, H.-J. Shin, J.-Y. Choi, V. E. Fedorov, Chemistry - An Asian Journal 2012, 7, 554; Y. Lin, T. V. Williams, W. Cao, H. E. Elsayed-Ali, J. W. Connell, The Journal of Physical Chemistry C 2010, 114, 17434.

[24] R. Geick, C. H. Perry, G. Rupprecht, Physical Review 1966, 146, 543.

[25] S. Anderson, R. L. Bohon, D. D. Kimpton, Journal of the American Ceramic Society 1955, 38, 370 .

[26] M. Du, X. Li, A. Wang, Y. Wu, X. Hao, M. Zhao, Angewandte Chemie International Edition 2014, 53, 3645.

[27] Y. Qiu, K. Park, Advanced Drug Delivery Reviews 2012, 64, Supplement, 49; X. Zhang, C. L. Pint, M. H. Lee, B. E. Schubert, A. Jamshidi, K. Takei, H. Ko, A. Gillies, R. Bardhan, J. J. Urban, M. Wu, R. Fearing, A. Javey, Nano Letters 2011, 11, 3239; C. Yu, Z. Duan, P. Yuan, Y. Li, Y. Su, X. Zhang, Y. Pan, L. L. Dai, R. G. Nuzzo, Y. Huang, H. Jiang, J. A. Rogers, Adv. Mater. 2013, 25, 1541.

[28] C. Zhi, Y. Bando, T. Terao, C. Tang, H. Kuwahara, D. Golberg, Advanced Functional Materials 2009, 19, 1857.

[29] Y. Agari, T. Uno, Journal of Applied Polymer Science 1986, 32, 5705.

[30] I. Jo, M. T. Pettes, J. Kim, K. Watanabe, T. Taniguchi, Z. Yao, L. Shi, Nano Letters $2013,13,550$.

[31] L. Lindsay, D. A. Broido, Physical Review B 2011, 84, 155421. 


\section{WILEY-VCH}

[32] X. Chen, P. Wu, M. Rousseas, D. Okawa, Z. Gartner, A. Zettl, C. R. Bertozzi, Journal

of the American Chemical Society 2009, 131, 890; L. Horváth, A. Magrez, D. Golberg, C.

Zhi, Y. Bando, R. Smajda, E. Horváth, L. Forró, B. Schwaller, ACS Nano 2011, 5, 3800.
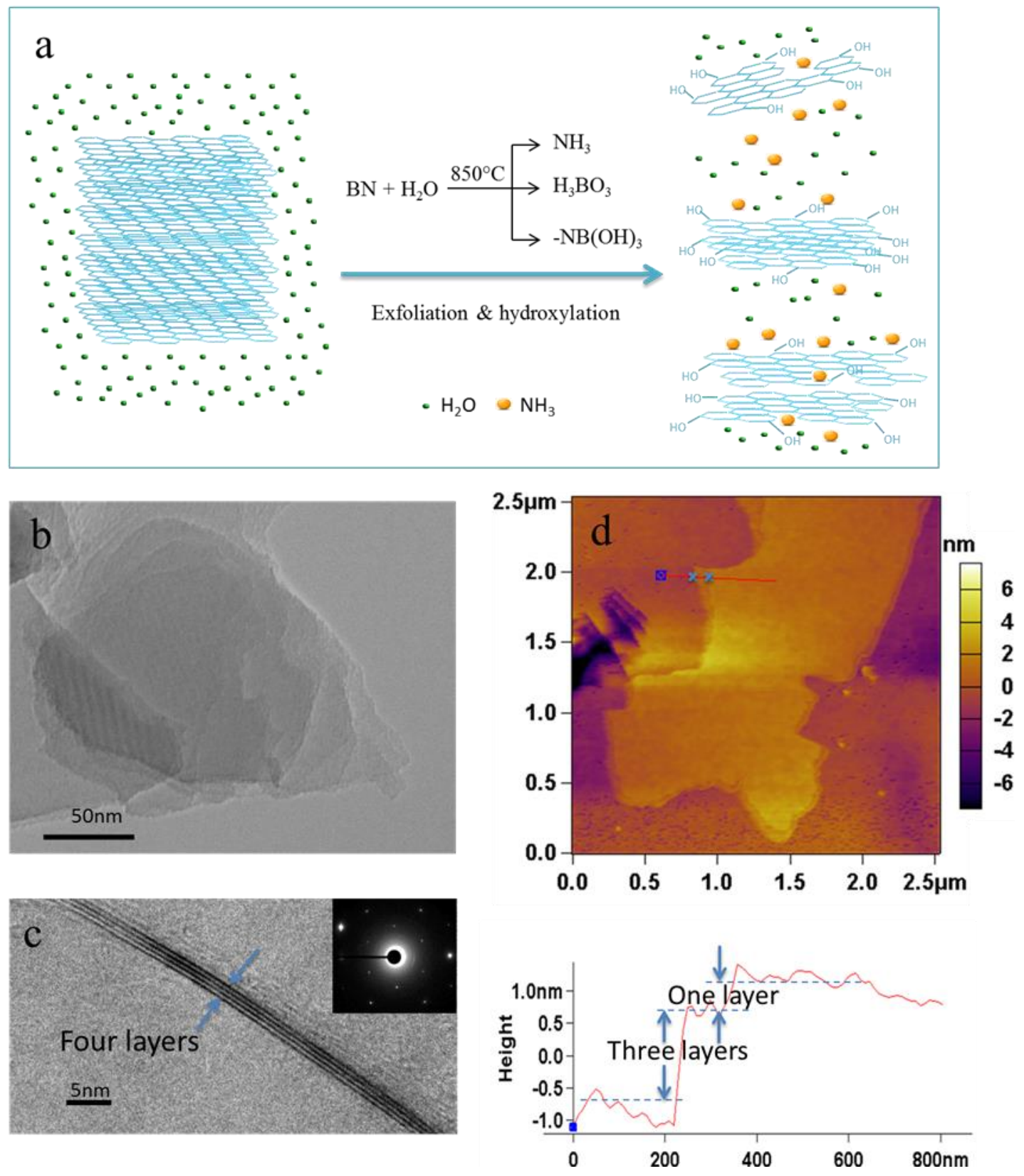

Figure 1. a) Schematic illustration of hydrolysis-assisted exfoliation and hydroxylation of $h$ BN powder in hot steam, where $\mathrm{H}_{2} \mathrm{O}$ reacts with $h$-BN, forming $\mathrm{NH}_{3}$ and $-\mathrm{NB}(\mathrm{OH})_{x}$, and the highly energetic $\mathrm{H}_{2} \mathrm{O}$ and $\mathrm{NH}_{3}$ assist the exfoliation through diffusion between $\mathrm{BN}$ layers; b) TEM image of a Moiré pattern due to the stacking of few-layered OH-BNNS; c) TEM image of four-layered $\mathrm{OH}-\mathrm{BNNS}$ (inset showing the corresponding electron diffraction pattern); d) 


\section{WILEY-VCH}

AFM topographic image and the corresponding height profile of $\mathrm{OH}-\mathrm{BNNS}$ showing a terraced morphology with a mono-layered OH-BNNS joined to a tri-layered OH-BNNS.
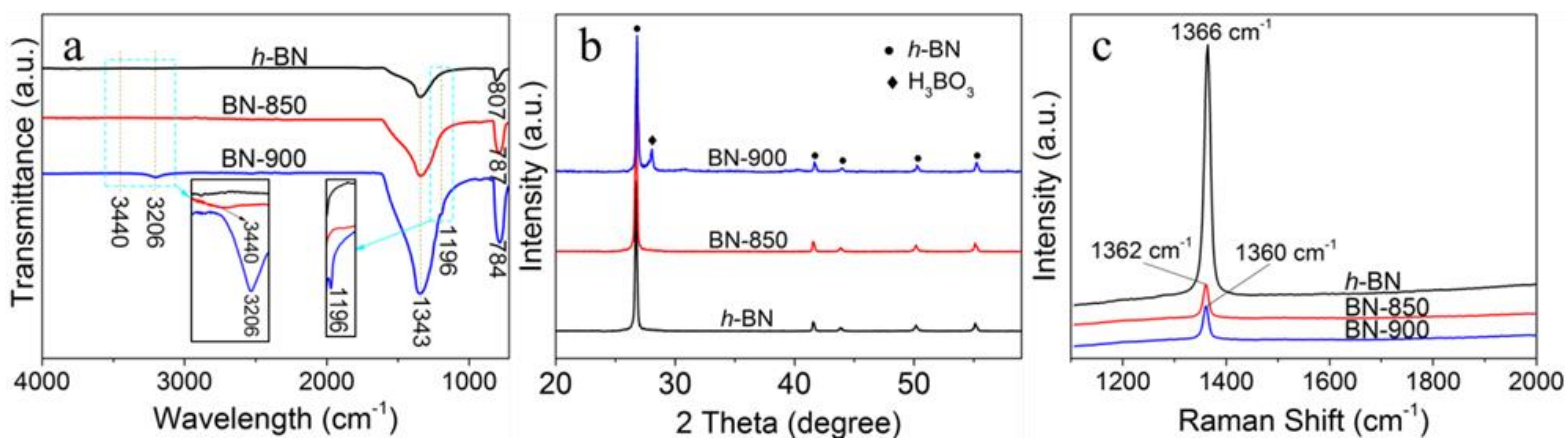

Figure 2. Pristine $h$-BN and $h$-BN treated at $850{ }^{\circ} \mathrm{C}$ (denoted as $\left.\mathrm{BN}-850\right)$ and $900{ }^{\circ} \mathrm{C}(\mathrm{BN}-$ 900). a) FTIR spectra showing the presence of only $-\mathrm{NB}(\mathrm{OH})_{x}$ in $\mathrm{BN}-850$, as opposed to the large amount of $\mathrm{H}_{3} \mathrm{BO}_{3}$ in $\mathrm{BN}-900$; b) XRD patterns revealing the presence of $\mathrm{H}_{3} \mathrm{BO}_{3}$ in $\mathrm{BN}-$ 900, which is negligible in $\mathrm{BN}-850$. c) The red-shifts in the Raman spectra of the $\mathrm{E}_{2 \mathrm{~g}}$ peak indicate the formation of few-layered $\mathrm{BN}$ at elevated temperatures.
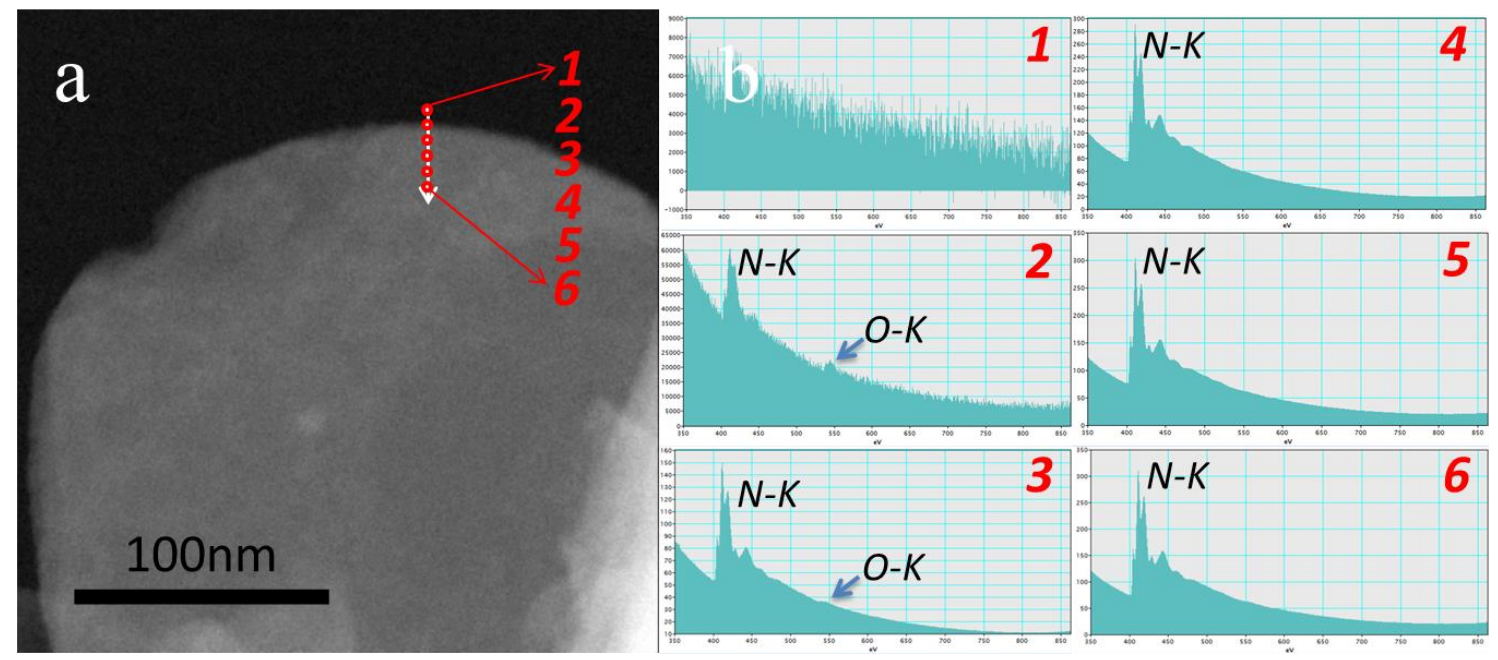

Figure 3. EELS mapping shows that the hydroxyl groups are predominately located along the edges of the nanosheets. Area 1 is off the BNNS so no O-K or N-K peaks are observed; on moving to the edge of the BNNS (area 2), the O-K peak appears and then becomes weaker on moving away from the edge (area 3 ). The O-K peak is not observed when moving further into the basal plane (areas 4, 5, and 6). The presence of $1 \mathrm{~s}-\pi^{*}$ and $1 \mathrm{~s}-\sigma^{*}$ peaks of the N-K edge confirm that the intrinsic hexagonal structure of $h$-BN still remains. 


\section{WILEY-VCH}

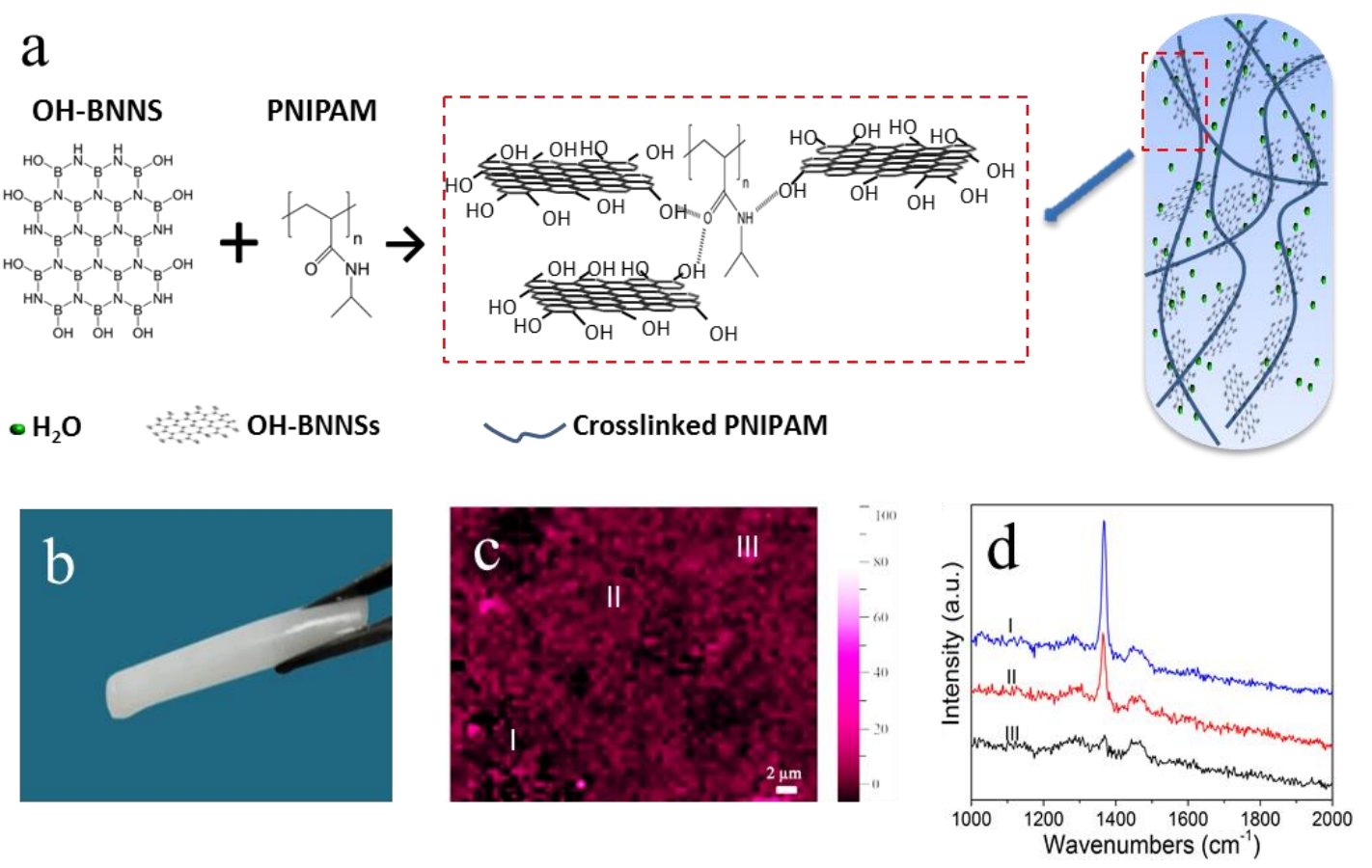

Figure 4. a) Schematic illustration of the formation of PNIPAM/OH-BNNS hydrogel, where the cross-linked PNIPAM and OH-BNNS are integrated through hydrogen bonding, b) photographic image of PNIPAM/OH-BNNS hydrogel, c) Raman mapping collected at 1362 $\mathrm{cm}^{-1}$, showing the uniform distribution of the OH-BNNS in the hydrogel network, and d) Raman spectra of three points with maximum (III), mean (II), and minimum (I) intensity, judged by human eyes. The featured peaks of PNIPAM (at $\sim 1450 \mathrm{~cm}^{-1}$ ) and OH-BNNS $\left(\sim 1360 \mathrm{~cm}^{-1}\right)$ have an independent existence. 


\section{WILEY-VCH}
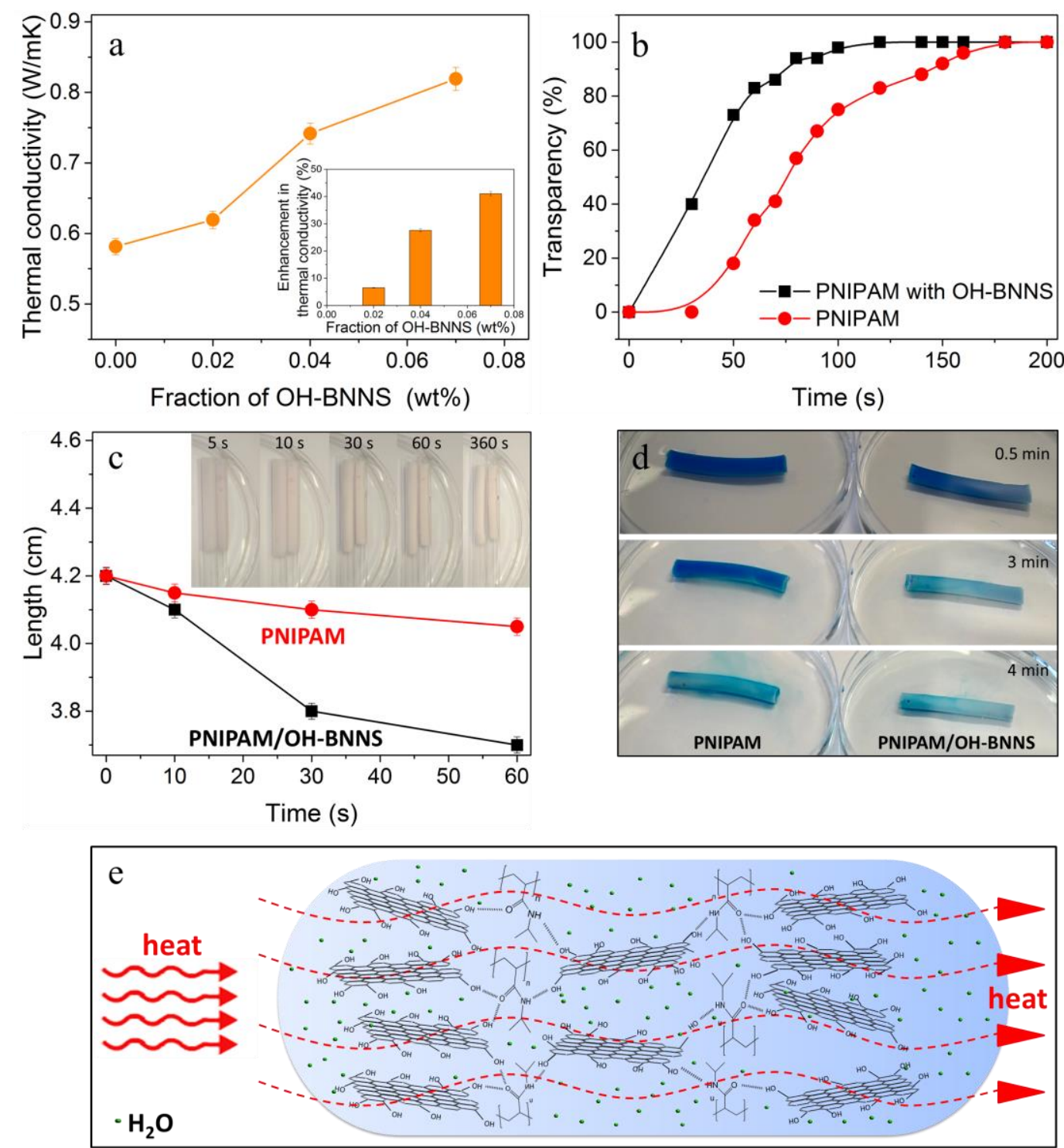

Figure 5. a) Thermal conductivity improvement with the ratio of OH-BNNS (inset: the improvement by percentage), b) change in transparency, c) change in length of cylindrical samples (inset: photographs of hydrogels at different times, with PNIPAM on the left and PNIPAM/OH-BNNS on the right), d) dye release upon heating, and e) schematic illustration of the enhanced heat transfer in PNIPAM/OH-BNNS hydrogel, which has resulted from the excellent integration between the $\mathrm{OH}-\mathrm{BNNS}, \mathrm{H}_{2} \mathrm{O}$, and the cross-linked PNIPAM through hydrogen bonding. 


\section{WILEY-VCH}

Table of contents

Upon flowing hot water steam over hexagonal boron nitride (BN) bulk powder, efficient exfoliation and hydroxylation of BN occur simultaneously. Through effective hydrogen bonding with water and $N$-isopropylacrylamide, edge-hydroxylated $\mathrm{BN}$ nanosheets dramatically improve the dimensional change and dye release of this temperature sensitive hydrogel and thereby enhance its efficacy in bionic, soft robotic, and drug delivery applications.

\section{Keyword}

boron nitride, nanosheets, hydroxyl, functionalization, temperature sensitive hydrogel

Feng Xiao, Sina Naficy, Gilberto Casillas, Majharul H. Khan, Tomas Katkus, Lei Jiang, Huakun Liu, Huijun Li, Zhenguo Huang*

Title

Edge-hydroxylated Boron Nitride Nanosheets as an Effective Additive to Improve the Thermal Response of Hydrogels

ToC figure

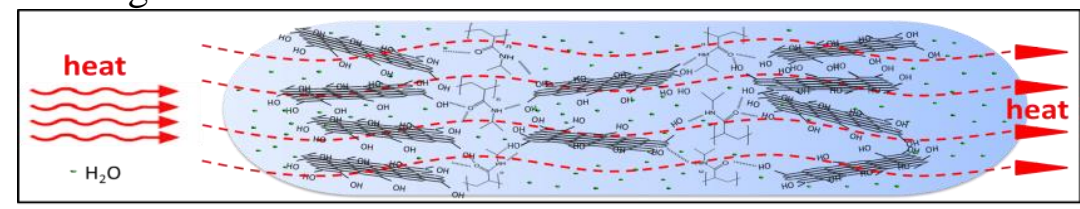

